\title{
Research on Agricultural Supply Chain: Sources and Preventions of Financial Credit Risk
}

\author{
Shuqin $\mathrm{Xu}^{1, *}$ \\ ${ }^{1}$ Harbin University, Harbin, Heilongjiang 150001, China \\ *Corresponding author. Email:961056440@qq.com

\begin{abstract}
The credit risk faced by developing agricultural supply chain finance includes external factors and internal factors. External factors include the natural environment, economic environment, legal environment, and credit environment. Internal factors include information asymmetry, core enterprise default, small and medium-sized agricultural products enterprise default. This paper aims to analyze the sources of financial credit risk in the agricultural supply chain, and then analyze the preventions of financial credit risk. Effective measures include government departments to improve the relevant legal system, strengthen the construction of the rural credit system. In contrast, commercial banks should continuously improve access mechanism, incentive mechanism, risk early warning mechanism, and risk emergency mechanism to prevent the credit risk of agricultural supply chain finance.
\end{abstract}

Keywords: agriculture, supply chain, financial credit risk

\section{INTRODUCTION}

Since the economic restructuring in 1979, China's rural financial system has been established and developed for nearly 40 years and has made remarkable achievements. However, the level of financial development in rural areas is still backward compared with the level of economic development and financial deepening in urban areas. The risk of credit seriously affects the stability and development of the rural financial system, which hindered the economic development of our country's rural areas. Due to the high risk of agricultural nature and the asymmetric information, the agriculture-related credit business of formal finance is facing the high risks and high transaction costs, thus, how to prevent the agricultural financial credit is the urgent issue for further research.

\section{AgRICULTURAL INDUSTRY CHAIN}

FINANCING AND AGRICULTURAL SUPPLY CHAIN FINANCE

Agricultural supply chain finance refers to the comprehensive management of logistics, information flow and capital flow by commercial banks around the core enterprises in the agricultural industry chain, including the upstream and downstream small and medium-sized enterprises, farmers, cooperatives and other business entities in each link, to provide comprehensive financial services for various business entities in the agricultural industry chain [1].

\section{MAIN TYPES OF AGRICULTURAL SUPPLY CHAIN FINANCE}

\section{A. Discount model of agricultural supply chain finance}

The discount model of agricultural supply chain finance is useful for solving the financing problems of small and medium-sized agricultural products enterprises located in the upstream of the agricultural industry chain. In general, core enterprises tend to take advantage of their strong position to delay payment to upstream SMEs. However, the discount model of agricultural supply chain finance can effectively alleviate the financial pressure on upstream SMEs caused by the delayed payment of core enterprises [2].

\section{B. Confirmed warehouse mode of agricultural supply chain finance}

Agricultural products are highly seasonal. Therefore the downstream SMEs tend to purchase large quantities of agricultural products at low prices to obtain cost advantages. This practice makes small and mediumsized enterprises in the lower reaches of the financial pressure. The confirmed warehouse mode of agricultural supply chain finance can effectively alleviate the above problems.

\section{SOURCES OF FINANCIAL CREDIT RISK IN AGRICULTURAL SUPPLY CHAIN}

From the perspective of the operation mode of agricultural supply chain finance, compared with 
traditional credit, it is more conducive to reducing the transaction risk of credit funds. However, it cannot altogether avoid the risk. Especially, credit risk is the most common and most concerned form of risk.

\section{A. Credit risk caused by external factors}

1) Credit risk caused by the natural environment: The modernization level of agricultural production in China is relatively low, and the ability to resist natural disasters is relatively poor. Therefore, the occurrence of natural disasters will have a serious impact on the production circle of agricultural industry chain. The risk of natural disasters can easily by transformed into the credit risk of business entities.

2) Credit risk arising from the economic environment: If the whole macro-economy fluctuates, it will affect the production of agricultural products at the source, or it may have an impact on the sales link of the agricultural industry chain, causing the unscheduled sales of agricultural products and making it difficult for commercial banks to recover loans.

3) Credit risk arising from the legal environment: Supply chain finance is a new form of finance, so it inevitably enters some legal blank areas [3]. In the implementation process of supply chain finance, a large number of mortgages guarantees of real rights of movables will be involved. However, China has not yet issued a special law on chattel guarantee, and the diversified characteristics of chattel mortgage guarantees in the existing legal provisions bring certain legal risks to commercial banks' mortgage business.

4) Credit risk caused by credit environment: Due to the backward credit awareness in rural areas and the low construction level of the credit investigation system, small and medium-sized agricultural products enterprises and farmers will have a strong incentive to make use of information advantages to seek profits, resulting in commercial banks unable to obtain real data and take effective management measures.

\section{B. Credit risk caused by internal factors}

1) Credit risk arising from information asymmetry: There is a complex game relationship among various principals involved in agricultural supply chain finance, and the enterprises will make use of their information advantages to carry out selfish actions ${ }^{[4]}$. In supply chain finance, the credit risk of a certain link will be transmitted to the whole supply chain, which may cause greater losses to the commercial banks.

2) Credit risk caused by core enterprises: As the hub of the whole agricultural industry chain, the credit level of the core enterprises themselves greatly affects the credit level of the whole industry chain. Once the core enterprise credit problems will be triggered and quickly transmitted to the whole supply chain.

3) Credit risk caused by small and medium-sized agricultural products enterprises: More obvious flaws of agricultural SMEs are the lack of scientific and complete financial data and its poorly repayment ability. Small and medium-sized agricultural products are difficult to provide full and effective collateral that in accordance with the requirements of the commercial banks. When adverse changes in external environment and own mismanagement, the probability of failing to repay the loan is very high.

\section{CONCLUSION AND COUNTERMEASURES}

\section{A. Improvement of relevant systems by government departments}

1) Improving the relevant legal systems: As a new type of financial form, agricultural supply chain finance is more complex than the traditional financial credit business. It involves the security law, property law, contract law, measures for the chattel mortgage registration, methods for registration of pledges of account receivable and so on a large number of laws and regulations. The existing provisions of these laws and regulations can't adapt to the requirements of supply chain finance development, thus the corresponding provisions of laws and regulations should be targeted to be modified and improved.

2) Strengthening the construction of rural credit system: At first, government departments can set up information sharing platform to promote communication and sharing among the agricultural supply chain financial stakeholders. Secondly, the government can also lead to set up the guarantee agencies involved in the agricultural supply chain finance, which help to reduce the credit risk of agricultural supply chain finance. Furthermore, the government should be committed to improve the rural credit system of small and medium-sized enterprises and farmers. The construction of rural credit system can improve the commercial banks to open exhibition of agricultural supply chain financial incentives.

\section{B. Institutional design for commercial banks to reduce credit risk}

1) Accessing mechanism design: For small and medium-sized agricultural products enterprises applying for agricultural supply chain financial services, commercial banks should restrict and screen them through strict access mechanism [5]. Commercial banks can reduce credit risk by setting a higher entry threshold. In addition, the credit risk control capability 
within the agricultural industry chain should be strictly inspected. For core enterprise assets, sales and credit level must carry on the comprehensive assessment and measure. Those can ensure the credit endorsement providers have strong operation and relatively high credibility.

2) Incentive mechanism design: Since commercial banks don't participate in the transactions between the enterprises within the supply chain, commercial banks need to design contracts to reduce the negative impacts. Incentive mechanism can make the enterprises have the motivation to participate in the supply chain finance and weaken the motivation of enterprise to default.

3) Design of credit risk warning mechanism: After obtaining the necessary information, commercial banks can identify, measure and control credit risks by establishing a risk warning model. The information needed to establish a risk early warning model is mainly composed of five types of information, such as exchange contract information, capital flow information, logistics information, market information and collateral information.

4) Credit risk emergency mechanism design: It is necessary to build a resilient network of agricultural supply chains to resist its effects. The strong elastic supply chain network can still maintain a certain degree of stability under the impact of sudden credit risks. It can reduce the harm of credit risks by shortening the process time of credit risks and improving the speed of supply chain response to sudden credit risks.

\section{References}

[1] Shuguang Wang. Institutional conditions and model innovation of agricultural supply chain finance in China $[\mathrm{J}]$. Research on rural finance, 2019(7):7-12.

[2] Tongjiang Zhu, Siyue Chen. Risk management of supply chain finance in commercial banks [J]. Times finance, 2018(3):325326.

[3] Jianyu Tao. Credit risk in corporate finance leasing and its prevention [J]. Economic and trade practice, 2018(1):120-120.

[4] Xiangyu Wu. The generation and prevention of credit risks in commercial banks from the perspective of information asymmetry [J]. Times finance,2017(8).

[5] Xiaohong Zou. Problems existing in the credit risk management process of Chinese commercial banks and countermeasures thinking [J]. Business economics, 2017(10):120-121.

[6] Zhou Yilu. Research on the Allocation efficiency of Agricultural Credit Funds in China [D]. Xinan University. 2010. 